\title{
Low level of extra-pair paternity in a population of the Barn Swallow Hirundo rustica gutturalis
}

\author{
Masaru HASEGAWA ${ }^{1, \#}$, Emi ARAI ${ }^{2}$, Wataru KOJIMA ${ }^{3}$, Wataru KITAMURA ${ }^{3}$, Go FUJITA $^{3}$, \\ Hiroyoshi HIGUCHI ${ }^{3}$, Mamoru WATANABE ${ }^{1}$ and Masahiko NAKAMURA ${ }^{2}$ \\ ${ }^{1}$ Graduate School of Life and Environmental Sciences, University of Tsukuba, 1-1-1 Tennoudai, Tsukuba-shi, \\ Ibaraki 305-8572, Japan \\ ${ }^{2}$ Laboratory of Animal Ecology, Department of Biology, Joetsu University of Education, 1 Yamayashiki-machi, \\ Joetsu-shi, Niigata 943-8512, Japan \\ ${ }^{3}$ Graduate School of Agriculture and Life Sciences, University of Tokyo, Tokyo 113-8657, Japan
}

\begin{tabular}{c}
\hline ORNITHOLOGICAL \\
SCIENCE \\
@ The Ornithological Society \\
of Japan 2010 \\
\hline
\end{tabular}

\begin{abstract}
On average, male birds other than social father sire more than $10 \%$ of all offspring. Levels of extra-pair paternity below 5\% of offspring are rarely found and are now considered worthy of explanation in monogamous birds. We recorded the lowest levels of paternity loss ever reported in a population of Barn Swallows Hirundo rustica. The levels of extra-pair paternity were below 5\% of offspring (7/243 in 2005 and 1/53 in 2006). We discuss our results in relation to the density-dependence of extra-pair paternity.
\end{abstract}

Key words Density-dependence, Extra-pair young, Hirundo rustica
Most socially monogamous birds are in reality not genetically monogamous due to extra-pair paternity (Griffith et al. 2002). On average, males other than the social father sire more than $10 \%$ of all offspring (Griffith et al. 2002). The occurrence of extra-pair paternity can be explained by the advantage of multiple mating at least for males (Andersson 1994; Griffith et al. 2002; Arnqvist \& Kirkpatrick 2005). Low levels of extra-pair paternity $(<5 \%)$ in monogamous birds are rarely found, and thus, are now considered worthy of explanation (e.g. Griffith et al. 1999; Robertson et al. 2001; Griffith et al. 2002).

The Barn Swallow Hirundo rustica is a monogamous bird and a famous model species used to study extra-pair paternity (reviewed in Møller 1994; Turner 2006). Several studies have described the occurrence of extra-pair paternity (or its cause, extra-pair copulation) in relation to male traits (e.g. tail length: Møller \& Tegelström 1997; plumage coloration: Safran et al. 2005; body condition: Kojima et al. 2009), male behaviour (e.g. mate guarding: Møller 1994), genetic compatibility (Kleven et al. 2005), and other parameters related to population dynamics (breeding density:

(Received 14 August 2010; Accepted 14 October 2010)

\# Corresponding author, E-mail: perorobomusadiobe@gmail.com
Møller 1994; breeding synchrony: Saino et al. 1999; population size: Safran 2007; reviewed in Turner 2006). Despite these exhaustive studies of extra-pair paternity in several populations, extra-pair paternity reported is consistently high in this species (ca. 20\%: reviewed in Turner 2006), especially in studies with ample sample size (>200: cf. Griffith et al. 2002). Here, we report the lowest level of paternity loss known in a population of Barn Swallows with ample sample size (total 296 nestlings), and discuss a possible explanation.

\section{METHODS}

The field study was carried out in 2005 and 2006 in a residential area of Joetsu City, Niigata Prefecture, Japan $\left(37^{\circ} 07^{\prime} \mathrm{N}, 138^{\circ} 15^{\prime} \mathrm{E}\right)$. Barn Swallows H. r. gutturalis nest here under the eaves of a covered sidewalk along the street and breed in a loose colony in this area (see Tajima \& Nakamura 2003). We inspected the nests every other day to record breeding events. This allowed determination of: (1) the laying date, which was expressed as the date on which the first egg of the first clutch was laid, and (2) clutch size. Laying date was estimated by backdating one egg per day from the date of the first record of eggs in 
the nest. To determine the hatching date, we inspected nests every day around the estimated hatching date (10 days after incubation).

Following the method used by Saino et al. (1999), we plotted all nests found in the study site on a map and measured the distance between the focal nest and the nearest asynchronous male (i.e. a neighbour whose mate laid their first egg more than eight days before or six days after the mate of the focal male). Only asynchronous males were used for the analyses, because males intensely guard their mates outside the period (i.e. during the fertile period of their mates), and, at least in European subspecies, all cuckoldry happens during this period (Saino et al. 1999). Although Saino et al. (1999) averaged the distance to the two nearest males, we considered only one male because of the high variability in the distance between the nests in our study site.

Adult swallows were captured in sweep nets while roosting at night. The birds were provided with a numbered aluminum ring provided by the Ministry of the Environment, Japan and an individual combination of two or three half-sized colour rings, which were made by splitting plastic rings (AC Hughes, Middlesex). Sex was determined by the presence (female) or absence (male) of an incubation patch, as only females have a brood patch in this species (Turner 2006). Nest ownership was subsequently determined with binoculars.

At capture, we obtained a small sample of blood from the brachial vein. The samples were preserved in Queen's lysis buffer $(0.01 \mathrm{M}$ Tris, $0.01 \mathrm{M} \mathrm{NaCl}$, $0.01 \mathrm{M}$ EDTA, and 1.0\% n-lauroylsarcosine, $\mathrm{pH} 8.0$; Seutin et al. 1991).

Nestlings were captured 12 days after hatching. Blood was collected from the brachial vein, and samples were preserved in Queen's lysis buffer, as for the adults.

We isolated genomic DNA of adult and nestling birds by using an IsoQuick nucleic acid extraction kit (ORCA Research, Bothell, WA, USA) and used polymerase chain reaction (PCR) to amplify five microsatellite loci (Table 1 in Kojima et al. 2009). We verified the presence of PCR product, and then samples were prepared for analysis on an ABI 3100 automated sequencer (Applied Biosystems). Genotypes were determined using GeneMapper ${ }^{\mathrm{TM}}$ software (Applied Biosystems). We used CERVUS, version 2.0 to calculate the exclusion probabilities for the first and second parents for each locus and to test for the presence of null alleles (Marshall et al. 1998).
Table 1. Percentage of extra-pair young in 2005 and 2006.

\begin{tabular}{lll}
\hline & Nestlings & Broods \\
\hline 2005 & $2.9 \%(7 / 243)$ & $7.4 \%(4 / 54)$ \\
2006 & $1.9 \%(1 / 53)$ & $9.1 \%(1 / 11)$ \\
\hline
\end{tabular}

We compared offspring genotypes at four loci, HrU3, HrU5, HrU6, and Pocc6, with their putative parents using CERVUS, version 2.0. We did not include $\mathrm{HrU} 10$ in the analysis due to the high frequency of null alleles. The four microsatellite loci had a total exclusionary power of 0.986 and 0.998 for the first and second parents, respectively. In 2005, three nestlings in two different nests out of 243 nestlings from 54 nests, showed a mismatch at all four loci with their putative mother. They were considered to be the result of intra-specific brood parasitism. There were no cases of brood parasitism in 2006. No other cases of a genetic mismatch between offspring and social mother were recorded. We subsequently compared the offspring's paternal alleles with the alleles of the putative father. The genotypes of 13 offspring were not compatible with the genotypes of their social father. Two offspring showed a mismatch at three loci and six at four loci out of four. These offspring were considered extra-pair young (EPY). Five showed a mismatch at just one locus, so in these cases we compared their genotypes at $\mathrm{HrU} 10$ with their social father. The results revealed that each offspring shared an allele with its putative father at HrU10. The exclusion probability of four non-mismatching loci in these chicks was $>0.998$ (see also Kojima et al. 2009). We concluded that the mismatches were caused by mutation and that the five offspring were within-pair young.

We used a non-parametric Mann-Whitney U-test to study the difference in ecological factors between broods with and without EPY after pooling the data across two years because of the small sample sizes. To account for duplicate observations results from seven males that bred in both 2005 and 2006, we used data from only a single year for each of these males. We used data from 2005 for four males and data from 2006 for the other three, which included one male with EPY in the brood.

\section{RESULTS AND DISCUSSION}

The levels of extra-pair paternity were below 5\% 

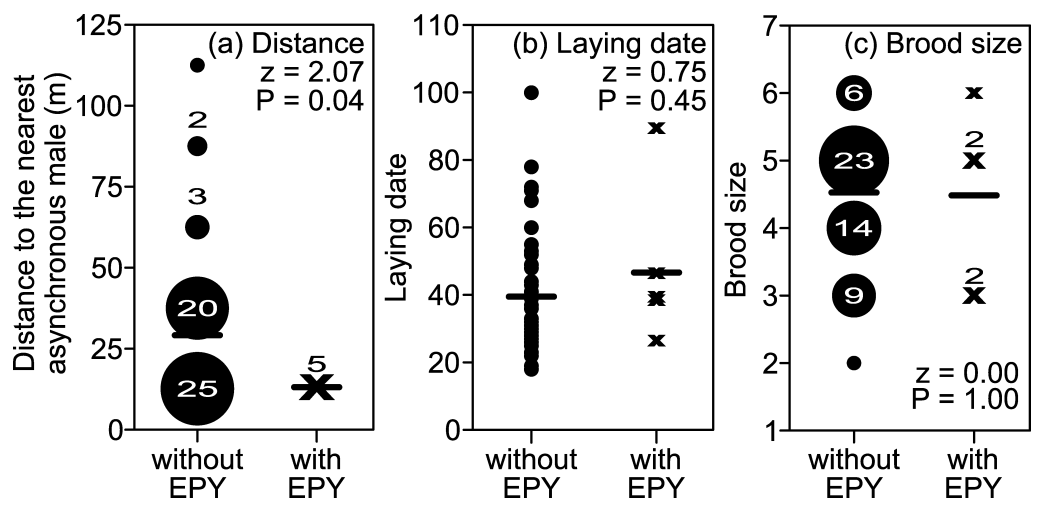

Fig. 1. Comparison of environmental variables between male Barn Swallows with (crosses) and without (filled circles) extra-pair young (EPY) in their broods: (a) distance to the nearest asynchronous male, (b) laying date (1 April $=1$ in each year), and (c) brood size. Numbers refer to number of individuals. Horizontal lines indicate the average values in each category. Mann-Whitney U-test was used for the statistical analyses.

of nestlings (2.9\% in 2005 and $1.9 \%$ in 2006) and below $10 \%$ of broods $(7.4 \%$ in 2005 and $9.1 \%$ in 2006) in both years (Table 1), and there were no significant differences in the level of EPY and nests containing EPY between the two years (both: $\mathrm{P}=1$, Fisher's exact test).

The observed level of EPY was the lowest among the results of the previous studies in European and North American subspecies (18-29\% of nestlings and $32-52 \%$ of broods had extra-pair young; reviewed in Turner 2006), and in studies of the colony breeders in the same subspecies in Japan (8-22\% of nestlings and $12-41 \%$ of broods; Kojima et al. 2009). This figure is also small compared with the paternity of birds in general (reviewed in Griffith et al. 2002).

The low EPY level we recorded in our study might have resulted from the low population density at our study site (mean \pm SD distance between the nearest males: $20.39 \pm 20.02 \mathrm{~m}, \mathrm{~N}=52$ ) compared with that of colony breeders in the same subspecies (the two colonies studied in Kojima et al. (2009); 6.18 \pm 7.71 $(\mathrm{N}=31)$; Kitamura personal communication; $\mathrm{t}=4.58$, $\mathrm{P}<0.01$ ) and in other subspecies (ca. 3-5 m; reviewed in Turner 2006). The mean distance (ca. $20 \mathrm{~m}$ ) to the nearest male in our population, would not physically constrain extra-pair copulation in Barn Swallows, because they have a large home range $(>100 \mathrm{~m}$; reviewed in Turner 2006). It may, however, be more difficult in a sparse population than in a dense population for males (or females) to watch for a chance to engage in extra-pair copulation with neighbours. Thus, we consider that population density may explain the low level of paternity loss in our population.

In accordance with this, the broods with EPY had the nearest asynchronous males significantly closer than broods without EPY within our population (Fig. 1a). The relationship was probably not confounded by laying date or brood size, because these variables did not differ between the two groups (Figs. 1b, c).

These results indicate that low population density explains the low level of paternity loss in our population. Our results are consistent with the general relationship in which extra-pair paternity decreases with lowering density within species (Westneat \& Sherman 1997; Møller \& Ninni 1998; reviewed in Griffith et al. 2002). However, the current argument is only based on correlative study. Further study is needed to determine whether low paternity loss in our population can be explained by low density with experimental manipulation (e.g. Ockendon et al. 2009).

\section{ACKNOWLEDGMENTS}

We are grateful to the residents of Joetsu City for their kind support and assistance. We also thank the members of the Laboratory of Animal Ecology of Joetsu University of Education and the Laboratory of Conservation Ecology of University of Tsukuba.

\section{REFERENCES}

Andersson M (1994) Sexual selection. Princeton Univ Press, Princeton.

Arnqvist G \& Kirkpatrick M (2005) The evolution of infidelity in socially monogamous passerines: the strength of direct and indirect selection on extrapair copulation behavior in females. Am Nat 165: S26S37.

Griffith SC, Stewart IRK, Dawson DA, Owen IPF \& 
Burke T (1999) Contrasting levels of extra-pair paternity in mainland and island populations of the house sparrow (Passer domesticus): is there an 'island effect'? Biol J Linn Soc 68: 303-313.

Griffith SC, Owens IPF \& Thuman KA (2002) Extra pair paternity in birds: a review of interspecific variation and adaptive function. Mol Ecol 11: 2195-2212.

Kleven O, Jacobsen F, Robertson RJ \& Lifjeld JT (2005) Extrapair mating between relatives in the barn swallow: a role for kin selection? Biol Lett 1: 389392.

Kojima W, Kitamura W, Kitajima S, Ito Y, Ueda K, Fujita G \& Higuchi H (2009) Female barn swallows gain indirect but not direct benefits through social mate choice. Ethology 115: 939-947.

Marshall TC, Slate J, Kruuk LEB \& Pemberton JM (1998) Statistical confidence for likelihood-based paternity inference in natural populations. Mol Ecol 7: 639-655.

Møller AP (1994) Sexual selection and the barn swallow. Oxford Univ Press, Oxford.

Møller AP \& Ninni P (1998) Sperm competition and sexual selection: a meta-analysis of paternity studies of birds. Behav Ecol Sociobiol 43: 345-358.

Møller AP \& Tegelström H (1997) Extra-pair paternity and tail ornamentation in the barn swallow Hirundo rustica. Behav Ecol Sociobiol 41: 353-360.

Ockendon N, Griffith SC \& Burke T (2009) Extrapair paternity in an insular population of house sparrows after the experimental introduction of individuals from the mainland. Behav Ecol 20: 305-312.

Robertson BC, Degnan SM, Kikkawa J \& Moritz OC (2001) Genetic monogamy in the absence of paternity guards; the Capricorn silvereye, Zosterops lateralis chlorocephalus on Heron island. Behav Ecol 12: 666-673.

Safran RJ (2007) Settlement patterns of female barn swallows Hirundo rustica across different group sizes: access to colorful males or favored nests? Behav Ecol Sociobiol 61: 1359-1368.

Safran RJ, Neuman CR, McGraw KJ \& Lovette IJ (2005) Dynamic paternity allocation as a function of male plumage color in barn swallows. Science 309: 2210-2212.

Saino N, Primmer CR, Ellegren H \& Møller AP (1999) Breeding synchrony and paternity in the barn swallow (Hirundo rustica). Behav Ecol Sociobiol 45: 211218.

Seutin G, White BN \& Boag PT (1991) Preservation of avian blood and tissue samples for DNA analyses. Can J Zool 69: 82-90.

Tajima K \& Nakamura M (2003) Response to manipulation of partner contribution: a handicapping experiment in the barn swallow. Ornithol Sci 2: 65-72.

Turner AK (2006) The barn swallow. T \& A D Poyser, London.

Westneat DF \& Sherman PW (1997) Density and extrapair fertilizations in birds: a comparative analysis. Behav Ecol Sociobiol 41: 205-215. 